INDIAN SECTION.

\title{
A Note on Leprosy and Sex.
}

\section{(Reprinted from "Leprosy in India," October, 1932.)}

\section{JoHN LOWE.}

$\mathrm{F}$ ROM conversations with leprosy workers in India we have found that there is a common idea among them that leprosy is more common among females up to the age of 30 and after that age it is more common among men. This idea seems to be based on the data concerning sex incidence given in Rogers and Muir's "Leprosy," pages 215 and 216. These data are based on the figures given in the 1921 Census Report for India. A careful reading of these two pages shows that the figures quoted give no evidence that leprosy is commoner among females up to the age of 30 . It must be admitted however that this particular section of Rogers and Muir's book is in many ways misleading and that it badly needs editing if not rewriting. One thing which is very misleading is the heading to Table XVIII, p. 216 which reads as follows "Sex incidence of leprosy at various age periods per 10,000 of each sex."

\begin{tabular}{|r|r|r|l|r|r|}
\hline \multicolumn{1}{|c|}{ Ages. } & Males. & Females. & Ages. & Males. & Females. \\
\hline & & & & & \\
$0-5$ & 45 & 92 & $35-40$ & 1,192 & 977 \\
$5-10$ & 103 & 200 & $40-45$ & 1,505 & 1,288 \\
$10-15$ & 256 & 433 & $45-50$ & 1,013 & 794 \\
$15-20$ & 416 & 646 & $50-55$ & 1,167 & 1,028 \\
$20-25$ & 591 & 779 & $55-60$ & 497 & 443 \\
$25-30$ & 892 & 939 & $60 \&$ over & 1,156 & 1,123 \\
$30-35$ & 1,193 & 1,170 & & & \\
& & & & & \\
\hline
\end{tabular}

We have studied the 1921 Census Report, and traced the figures on which this table is based. The heading of this table on the Census Report is "Distribution of the infirm (lepers) by age per 10,000 of each sex." This again is a little ambiguous. What it really means is "Distribution of leprosy by age, per 10,000 lepers of each sex" i.e., ten thousand male lepers at the time of the census are distributed in the various age periods as shown in the table, and similarly with 10,000 female lepers. The table now becomes understandable. It tells us nothing about the relative incidence of leprosy in the two sexes, but it does tell us that at the time of the census a larger proportion of the total number of 
female lepers were below 30 years of age, and a smaller proportion above 30 years of age, than was the case with male lepers. There are several possible explanations of this. It may be that the death rate among female lepers is higher than among males. This is Rogers and Muir's explanation, but it is not supported by the above table ; for the proportion of lepers of each sex aged 60 and over is about the same. A second possible explanation is that in females the disease may appear at an earlier age than in males, or another possibility is that susceptibility to leprosy in childhood is roughly equal in the two sexes but that in adult life males are more susceptible than females. All these ideas are very hypothetical and are based on figures of very doubtful reliability so we will not discuss this matter any further. We might however, discuss briefly the matter of relative sex incidence. The 1921 Census Report gives the following figures for all India 74,293 males 28,220 females, total 102,513 .

The age distribution of these for each sex is shown in the graph here reproduced.

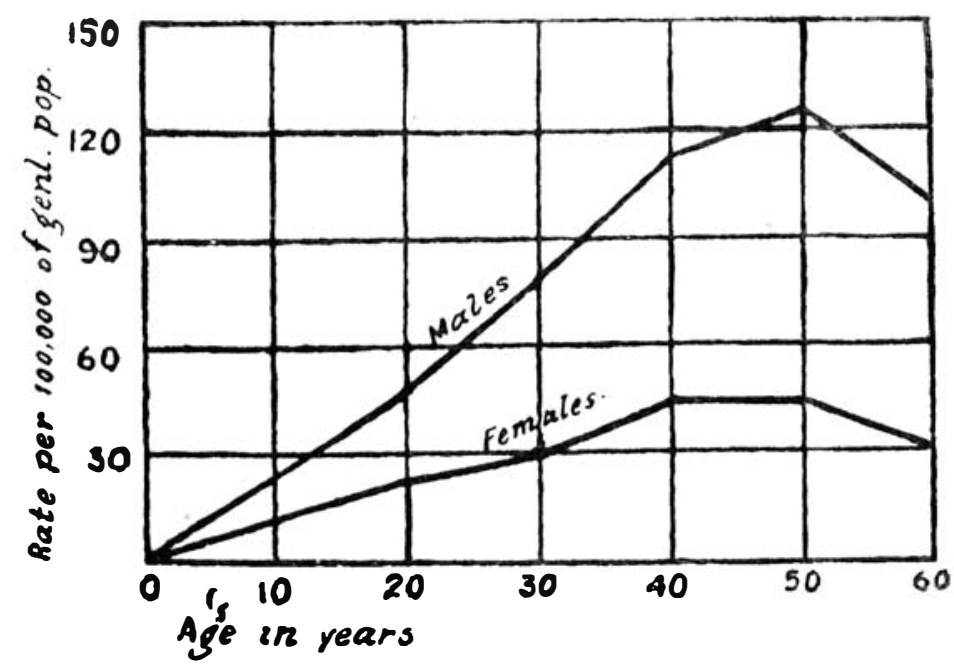

Thus the incidence of leprosy among males appears to exceed the incidence among females at all age periods.

Other information on the subject can be obtained from :-

(a) Leprosy institution reports which usually show a proportion of about four males to one female.

(b) Out-Patient clinics which usually show a proportion of six or eight males to one female.

(c) Survey reports which usually show a proportion of several males to each female. 
Are these figures reliable? Almost certainly not. The census officers are all males, the doctors running leprosy surveys, clinics, institutions, etc., are mostly male, and owing to the seclusion of Indian women it is very difficult for such workers to find out the truth about leprosy among females. Women find much greater difficulty than males in leaving their homes to attend hospital and clinics. The facts about the prevalence of leprosy among females must be ascer-tained by special methods. The relative incidence in childhood can be ascertained by systematic examination of school children of both sexes. One such investigation has been made in Travancore where of 2,000 boys of school age about 1 per cent. showed signs of leprosy, and of 2,000 girls of school age about 1 per cent. showed signs of leprosy. Regarding the relative incidence in the two sexes later in life it is difficult to get accurate information. Work on a voluntary basis will only reveal a small proportion of the women lepers. The leprosy clinics run by the staff of Women's Medical College, Vellore, report a very small proportion of female patients. Compulsory medical examination of coolie labour in industrial areas may provide some valuable data.

Dr. B.N. Ghosh has kindly provided me with the following figures based on a survey of an industrial area in which all coolie labour male and female was compulsorily examined.

\begin{tabular}{|c|c|c|c|}
\hline $\begin{array}{l}\text { Males examined } \ldots \\
\text { Cases of leprosy detected } \\
\text { Incidence in males } \ldots\end{array}$ & $\begin{array}{l}\cdots \\
\ldots\end{array}$ & $\begin{array}{l}\cdots \\
\cdots \\
\cdots\end{array}$ & $\begin{array}{r}109,471 \\
993 \\
.9 \%\end{array}$ \\
\hline $\begin{array}{l}\text { Females examin } \\
\text { Cases of lepros } \\
\text { Incidence in fer }\end{array}$ & & & $\begin{array}{r}21,977 \\
262 \\
1 \cdot 2\end{array}$ \\
\hline
\end{tabular}

Here the incidence in females is higher than that in males.

In another industrial survey, the figures for which have been given to me by $\mathrm{Dr}$. K. R. Chatterji, investigation of sex incidence gave different figures :

No. of men examined $\quad \ldots \quad \ldots \quad 86,789$

No. of cases of leprosy detected ... $\quad 1,489$

Incidence in males ... $\ldots \quad \ldots \quad 1 \cdot 7 \%$

No. of women examined $\ldots \quad \ldots \quad \mathbf{8 6 , 0 8 1}$

No. of cases of leprosy detected $\quad . . \quad 813$

Incidence in females $\quad \ldots \quad \ldots \quad . .9 \%$

Here the incidence in males in this industry was nearly twice the incidence among females. 
An investigation of labour conditions in these two industries reveals certain factors which may explain these differences in sex incidence. In the first industry living conditions are very bad, the work is indoors and rather unhealthy, and the women, in addition to working all day, have to work in their overcrowded quarters in the mornings and evenings; also some of the women have from time to time to bear the burden of pregnancy and childbirth. These bad conditions weigh very heavily on the women and they show a higher incidence of leprosy than the men.

In industry No. 2 with a low female incidence, conditions are very different. The work is light healthy outdoor work, the living quarters are good and conditions are in most respects excellent. The women work outside all day and work in the house in the early morning and evening. They are the real supporters of the family. The men do less work and after the age of 30 of ten do no work at all, but stay at home and look after the children while the mother works. The men become lazy and of ten dissolute and drunken, but the women remain hard working and healthy and suffer much less from diseases such as leprosy.

These facts indicate that in conditions under which coolie labourers sometimes live, leprosy may in some cases be even commoner among women than among men. If, as is commonly supposed, the number of male lepers in India exceeds the number of female lepers, the preponderence of male lepers is probably not due to a greater susceptibility to the disease but to a greater exposure to infection. The greater exposure of males to infection is seen on studying family life in villages. It is seen at all ages even in childhood when the susceptibility to leprosy is greatest. A female child is of ten unwanted and stays in the house where no one takes much notice of her. At an early age she is expected to work in the house and of ten becomes the family drudge. She probably does not go to school and moves out of the house but little. As puberty approaches, custom, tradition and modesty limit even further her activities and movements. After puberty, marriage quickly follows and then family ties and duties confine her more than ever to the home. Thus her contacts outside the house are very limited and unless there is leprosy in the house there is little chance of her contracting the infection.

With a male child it is very different. He is greatly prized and petted and all the neighbours (among whom there may be cases of leprosy) want to pick him up, nurse and fondle him. As he grows older he has very much more 
freedom than do girls. He may go to school, and he is not expected to work at such an early age as are girls. He moves quite freely about the village, possibly visiting the houses of lepers, who will not hesitate to call him into their home and make a fuss of him. Later on he goes to work, may move to other parts in search of work, and on the whole, lives a life of greater freedom and wider contacts than do females. This greater freedom means greater exposure to infection, and the male leprosy rate is higher than the female leprosy rate. When the seclusion of women is broken down, as it is with women coolies a greater number of women develop leprosy, and, in fact, under bad conditions the rate among women may exceed that among men.

This seems a probability but before making final deductions from such figures as these we must try to exclude possible fallacies. One possibility is that women belonging to families in which there is leprosy and women suffering from leprosy in a slight form cannot get married, and in order to support themselves they migrate to industrial areas and take up coolie work. I am informed that this factor probably did not operate markedly in the two industries quoted.

\section{Age Distribution.}

The age distribution of leprosy in the two sexes in an industrial survey was as follows :-

$\begin{array}{lcccccr}\text { Age } & 14-20 & 28-30 & 31-40 & 41-50 & \text { Over } 50 & \text { Total } \\ \text { Males } & 13 \% & 33 \% & 40 \% & 17 \% & 7 \% & 100 \\ \text { Females } & 11 \% & 21 \% & 40 \% & 24 \% & 4 \% & 100\end{array}$

This shows that contrary to the 1921 census figures the proportion of female lepers below the age of 30 is lower than the proportion of male lepers.

We have arrived provisionally at the following conclusions.

1. In India male lepers preponderate over female lepers.

2. This preponderance is seen at all ages.

3. The difference in incidence of leprosy on the two sexes is not due to any greater immunity to leprosy possessed by females but to the less exposure to infection of females owing to the more secluded life they usually live in India.

4. When the seclusion is broken down and women live under the same conditions as men, the leprosy rate among women may rise as high as or even higher than that among men.

The conclusions are provisional. The whole question of leprosy and sex needs further investigation. 